\title{
Tagging quantitative trait loci for dormancy, tuber shape, regularity of tuber shape, eye depth and flesh colour in diploid potato originated from six Solanum species
}

\author{
J. Śliwka ${ }^{1}$, I. WASilewiCZ-Flis ${ }^{1}$, H. JAKUCZUN ${ }^{1}$ and C. GebhardT ${ }^{2}$ \\ ${ }^{1}$ Plant Breeding and Acclimatization Institute, Młochów Research Centre, ul. Platanowa 19, 05-831 Młochów, Poland, E-mail: \\ j.sliwka@ihar.edu.pl; ${ }^{2}$ Max Planck Institute for Plant Breeding Research, Carl-von-Linné Weg 10, 50829 Cologne, Germany \\ With 2 figures and 2 tables
}

Received March 28, 2007/Accepted April 25, 2007

Communicated by F. Salamini

\begin{abstract}
Potato breeding aims at breeding diversified cultivars not only suitable for different purposes, but also resistant to diseases, such as late blight caused by Phytophthora infestans, which is a major constraint in potato production. Resistance to $P$. infestans has been previously introduced into the diploid hybrid population 98-21 from Solanum verrucosum and Solanum microdontum. In the present study, we assessed the segregation of tuber dormancy, tuber shape, regularity of tuber shape, eye depth and flesh colour in this population. Quantitative Trait Loci (QTLs) affecting these important quality traits were tagged using the genetic map developed for this population to locate QTLs for late blight resistance. The most prominent QTL for dormancy was detected on chromosome II and explained $7.1 \%$ of the variance. The most important QTLs for tuber eye depth, flesh colour, shape and shape regularity were identified on chromosomes X $\left(R^{2}=14.7 \%\right)$, IV $\left(R^{2}=\right.$ $5.8 \%)$, II $\left(R^{2}=8.0 \%\right)$ and III $\left(R^{2}=10.4 \%\right)$ respectively. All traits were also affected by minor QTLs. The obtained results improve our understanding of the inheritance of traits relevant for variety development in potato.
\end{abstract}

Key words: dormancy — eye depth — flesh colour quantitative trait loci — Solanum — tuber shape — regularity of tuber shape

In the year 2005, 321 million tons of potatoes (Solanum tuberosum L.) were produced in approximately 125 countries (FAOSTAT 2006). They were consumed fresh or processed, by more than a billion people, an increasing number of Chinese, Indians and Africans among them (Mullins et al. 2006). To meet demands of specific potato markets, potato breeders select new cultivars from 100000 seedlings in 11-12 years taking into account at least 50 different traits (Zimnoch-Guzowska 2002). Those traits are both qualitative and quantitative. Most of the underlying genes are still unknown. Desirable alleles influencing different traits are sought after among wild relatives of the potato and are introduced into the cultivated potato gene pool. Unfortunately, such widening of the gene pool can also result in the introgression of unwanted alleles.

To achieve commercial success, modern table and processing cultivars of potato have to fulfil stringent requirements concerning tuber quality traits. Tuber dormancy, shape and regularity of shape, eye depth and flesh colour as investigated in this study, are of significant importance.

Dormancy (resting period) of potato tubers is the physiological state after harvest, during which tubers do not sprout (Reust 1986) even when stored under conditions favourable for sprouting (Van den Berg et al. 1996a). Long dormancy assures the maintenance of good tuber quality after storage for as long as 7 months (Tarn et al. 1993). Commercially, sprouting has been controlled with chemical sprout inhibitors for more than 40 years (Van den Berg et al. 1996a). However, more and more consumers expect potatoes free from chemical residues. The importance of long dormancy of cultivars therefore increases (Tarn et al. 1993). Two molecular mapping studies detected a number of quantitative trait loci (QTLs) for tuber dormancy and demonstrated the complex character of this trait (Freyre et al. 1994, Van den Berg et al. 1996a).

Selecting for regular shaped tuber with shallow eyes is a very important objective in breeding for tuber quality. Usually, approximately $80 \%$ of the genotypes are discarded due to unacceptable tuber shape and eye depth at the single plant stage, even in progeny of cultivar by cultivar crosses (Kerlan and Ellisèche 2000). Tuber shape varies from compressed to long and is measured by the ratio of length to width. Consumers' and processing industry's preferences vary depending on the country and type of the product. Cultivars with long tubers are used for French fries, while cultivars with round tubers are preferred for crisps (Van Eck et al. 1994). Data on the inheritance of tuber shape were contradictory, whether round or long shape is dominant (Ortiz and Huaman 1994). The issue was solved by molecular mapping, which identified a single locus on chromosome X, with a dominant allele $R o$ conferring round tuber shape (Van Eck et al. 1994). In another study, where the mapping population consisted of interspecific hybrids between S. tuberosum and Solanum vernei, three QTLs influencing tuber shape were identified (Sørensen 2006).

The most complex and least investigated, but important trait in potato breeding is the regularity of tuber shape. It depends on the depth of indentations at the rose and the heel end and on all other deviations from ideal shape (Domański 2001). No genetic analysis has been performed so far for tuber shape regularity.

Eye depth is also an important component of tuber quality, because deep eyes make the tuber appearance worse and add to the cost of peeling in processing ( $\mathrm{Li}$ et al. 2005). As for tuber shape, contradictory hypotheses were formulated to explain the inheritance of eye depth (Ortiz and Huaman 1994, Li et al. 2005). Recently, the locus Eyd with a dominant allele conferring deep eyes has been discovered on chromosome X, linked with $4 \mathrm{cM}$ to $R o$ ( $\mathrm{Li}$ et al. 2005).

Tuber flesh colour varies from white to orange and colour preference depends on the country or, as in Poland, on the region 
of the country. The yellow flesh colour is controlled by the single dominant allele $Y$ at the $Y$ locus on potato chromosome III (Bonierbale et al. 1988). Another allele at the same locus, named Or, encodes orange flesh colour (Brown et al. 1993).

The goal of our study was to identify with DNA-based markers of known position on the 12 potato chromosomes loci, which influence tuber dormancy, shape, regularity of shape, eye depth and flesh colour in the population 98-21 having a number of wild species introgressions (Śliwka et al. 2007), and to compare them with loci detected in previous studies performed in populations with different origins.

\section{Materials and Methods}

Plant material: The diploid potato mapping population $98-21(2 \mathrm{n}=$ $2 x=24)$ consisted of 156 individuals and was obtained by crossing the hybrid clones DG 83-1520 (P1) and DG 84-195 (P2), described in Śliwka et al. (2007). Based on the pedigree information, the maternal clone DG 83-1520 consisted of $37.6 \% \mathrm{~S}$. tuberosum (three different dihaploids of $S$. tuberosum), 28.1\% S. chacoense (GLKS 66.51/6/6; PK $133), 12.5 \%$ Solanum verrucosum (PI 195170), 12.5\% Solanum microdontum (PI 265575), 6.2\% S. gourlayi (INTA. 7356) and 3.1\% Solanum yungasense (GLKS 67.107/3R), whereas the paternal clone DG 84-195 consisted of $81.3 \%$ S. tuberosum (five different dihaploids of S. tuberosum) $15.6 \%$ S. chacoense (GLKS 66.51/6/6; CPC 3785) and $3.1 \%$ S. yungasense (GLKS 67.107/3R). Population $98-21$ was planted in the field in 2 years in April $(20.04 .2002,28.04 .2003)$ and harvested in September $(20.09 .2002,23.09 .2003)$. Tubers were harvested and then stored at $7-9^{\circ} \mathrm{C}$.

Tuber dormancy: As an indicator of tuber dormancy, sprouting was evaluated in the beginning of February 2003 and 2004, after 4 months of storage. Each clone was evaluated on the basis of sprouting of whole yield harvested from seven hill-plots. We used a scale from 0 to 5 , where 0 indicates lack of sprouting in the majority $(>50 \%)$ of yield, $1=0.1-5 \mathrm{~mm}, \quad 2=6-50 \mathrm{~mm}, \quad 3=51 \mathrm{~mm}-$ $100 \mathrm{~mm}, 4=101 \mathrm{~mm}-150 \mathrm{~mm}$ length of sprouts and 5 indicates sprouts longer than $151 \mathrm{~mm}$.

Tuber shape was determined in 2003 according to Domańsk (2001), who described six types of tuber shape, which were transformed into numerical scores from 1 to 6 , where $1=$ long, $2=$ long oval, $3=$ oval, $4=$ round oval, $5=$ round and $6=$ compressed. For clones having tubers with different shapes, mean values of the grades were calculated.

Regularity of tuber shape was evaluated in 2003, using a 1-9 scale, where one means highly malformed tubers and nine means perfectly shaped tubers, taking into account the depth of indentations at the rose and heel end of the tuber, shape uniformity within the clone and other deviations from ideal shape (Domański 2001).

Eye depth was scored in 2003, using a 1-9 scale, where nine means eyes impalpable under the finger and one means eyes deeper than $5 \mathrm{~mm}$ (Domański 2001).

Tuber flesh colour was evaluated in January 2003. It was assessed visually on five tubers per clone according to a 1-6 scale, where $1=$ white, $2=$ grey white, $3=$ creamy white, $4=$ pale yellow, $5=$ yellow, $6=$ deep yellow flesh colour

Marker analysis and map construction: The population 98-21 was genotyped by polymerase chain reaction for 73 segregating marker alleles distributed on all 12 potato chromosomes as described previously (Śliwka et al. 2007). Mapping was performed with the software package MAPRF (E. Ritter, NEIKER, 01080, Victoria, Spain; Ritter et al. 1990). The map consisted of 35 and 38 marker alleles inherited from DG 83-1520 and DG 94-195 respectively. The marker alleles were assembled into separate parental linkage groups for DG 83-1520 and DG 84-195. Linkage groups were joined on the basis of 17 codominant markers.
Statistical analyses: Normal distribution of the phenotypic data was checked with the Kolmogorov-Smirnov test. The relationships between the traits were evaluated by linear Pearson's correlation coefficients. Marker/trait linkages were estimated by the MannWhitney's $U$-test. We chose the non-parametric Mann-Whitney's $U$-test for marker/trait linkage analysis because the distributions of all the investigated traits deviated from normality, most likely due to discontinuous assessment in scales and limited range of grades. Marker/trait linkages at $\mathrm{P} \leq 0.010$ were considered significant. Additionally, marker/trait linkages of markers located closely to the QTLs and significant at $\mathrm{P}<0.05$ were noted. The effects of QTLs were presented as percentage of variance explained by the markers, calculated by ANOvA. The effects of interactions between markers were estimated by a two-way ANOvA. All statistical analyses were performed using computer programs SPSS 10.0 for Windows (SPSS Inc., Chicago, IL, USA) and statistica for Windows (Stat Soft, Inc., Tulsa, OK, USA).

\section{Results}

The parent DG 83-1520 (P1) sprouted weakly (grade 1), its tubers were round-oval (3.5) with fairly good regularity of shape (6), medium shallow eyes (6) and grey-white tuber flesh (2). The parent DG 84-195 (P2) had similar dormancy (grade 1), round tubers (5.2) of slightly worse shape regularity (5.2), medium to medium-shallow eye depth (5.5) and pale-yellow tuber flesh (4). All phenotypic traits evaluated in the progeny 98-21 deviated from normality (Fig. 1). Sprouting varied from grade 0 (tubers completely dormant on 139th day of storage in 2003 or on 135th day in 2004) to grade 5 in 2003 (sprouts longer than $151 \mathrm{~mm}$ on 139th day of storage) and grade 4 in 2004 (sprouts between 101 and $150 \mathrm{~mm}$ of length on 135th day of storage). Almost the full range of tuber shapes was observed in population 98-21, from grade 1 (long) to 5.5 (between round and compressed). Neither highly malformed tubers were noted nor perfect ones. The lowest score of tuber shape regularity was four $(20-50 \%$ of weakly expressed faults such as protuberances among eyes, spindle or pear-shaped tubers; different types of shapes present; indentations $<2-3 \mathrm{~mm}$ ) and the best score was 6 (fairly good shape regularity, different types of shapes may be present, indentations $<1.6-2.6 \mathrm{~mm}$ ). The range of eye depths was narrowed to grades from 4 (3.1-4.0 mm of depth) to $6.5(1.3-2.0 \mathrm{~mm})$. Flesh colour varied from greywhite (score 2) to yellow (score 5).

Significant correlations were detected between tuber shape and shape regularity, eye depth and shape regularity and tuber shape and eye depth. Round tubers were usually more regular than the long ones $(r=0.361, \mathrm{P}<0.001)$. Shallow eyes were correlated with higher regularity $(r=0.446, \mathrm{P}<0.001)$. Round tubers tended to have deeper eyes $(r=-0.186$, $\mathrm{P}<0.05)$. Significant linkages between markers and QTLs were detected for 35 marker alleles, 11 at $\mathrm{P}<0.01$ and 12 at $\mathrm{P}<0.001$ for at least one trait and 12 remaining at $\mathrm{P}<0.05$ (Table 1). The traits investigated here were not significantly correlated with resistance to Phytophthora infestans and mean tuber weight that were analysed in the same population (Śliwka et al. 2007).

\section{Tuber dormancy QTLs}

Quantitative trait loci influencing the dormancy of tubers after 4 months of storage were identified on chromosomes II, V and IX (Table 1, Fig. 2). The most significant QTL was located on chromosome II with the maximum effect close to markers 

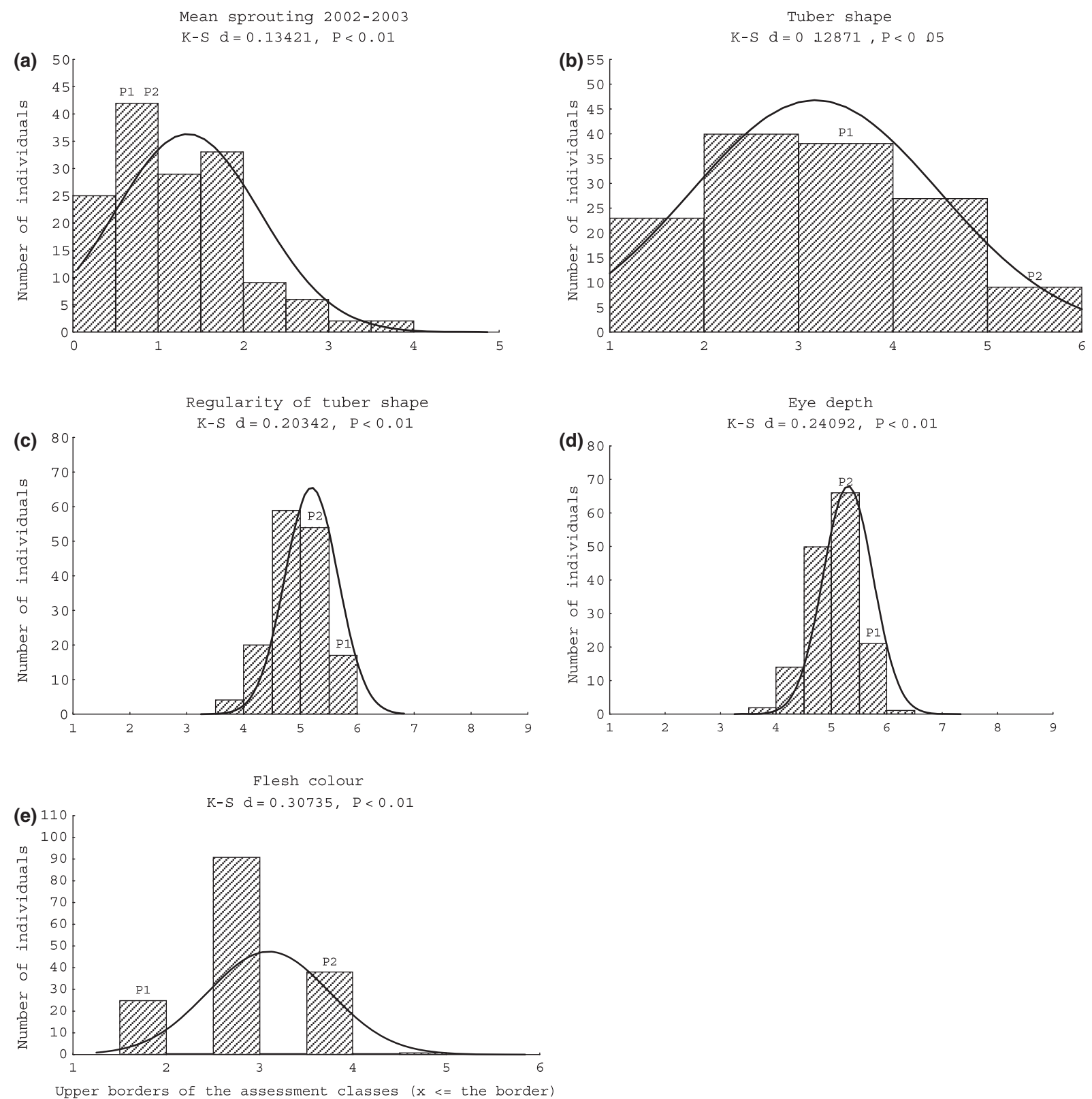

Fig. 1: Distributions of mean (2002-2003) sprouting (a), tuber shape (b), regularity of shape (c), eye depth (d) and flesh colour (e) in population 98-21 and their fitness to the normal curve. K-S - Kolmogorov-Smirnov test, $\mathrm{d}$ - coefficient calculated for this test, $\mathrm{P}$ - probability, the line indicates the normal curve. The scale of assessment depends on the trait, see Materials and Methods. Trait scores of parental clones are marked: P1 - DG 83-1520, P2 - DG 84-195

GP86 and GP321a. Alleles at these loci descending from both parents were significantly linked with sprouting and contributed to shorter dormancy period. The effect of the P1 alleles on sprouting was significant in 2004 and for the 2 year mean (2003-2004), while the effect of the P2 alleles was significant in all data sets, although less significant in 2004 (Table 1). The QTL for sprouting on chromosome $\mathrm{V}$ was also detected in all data sets, whereas the QTL on chromosome IX affected only mean sprouting and sprouting in 2004 (Table 1). The QTL for sprouting on chromosome II (P2) linked to marker GP321a explained $9.2 \%$ of the variance in 2003 and $7.1 \%$ of the variance for mean sprouting. QTLs on chromosomes V and IX explained up to $6.3 \%$ and $5.4 \%$ of the variance respectively (Table 2).

\section{Tuber shape QTLs}

The most important QTL for tuber shape was detected also on chromosome II. It was inherited from P2 and the most significant StPAD4 marker allele was linked with longer tuber shape and explained $8.0 \%$ of the variance in tuber shape. A second QTL for tuber shape was identified on chromosome XI. The allele also descending from $\mathrm{P} 2$ conferred rounder tubers and explained $5.6 \%$ of the variance (Tables 1 and 2 ).

\section{Regularity of tuber shape QTLs}

Three QTLs for this trait were tagged with the markers. The first one was located on chromosome III (Fig. 2). Significant 
Table 1: Significant marker-trait linkages calculated by Mann-Whitney's $U$-test

\begin{tabular}{|c|c|c|c|c|c|c|c|c|}
\hline $\mathrm{Ch}$ & $\begin{array}{l}\text { Marker and its } \\
\text { parental origin }\end{array}$ & $\begin{array}{l}\text { Sprouting } \\
2003\end{array}$ & $\begin{array}{l}\text { Sprouting } \\
2004\end{array}$ & $\begin{array}{l}\text { Sprouting } \\
\text { mean }\end{array}$ & $\begin{array}{l}\text { Tuber } \\
\text { shape }\end{array}$ & $\begin{array}{c}\text { Regularity of } \\
\text { shape }\end{array}$ & $\begin{array}{l}\text { Eye } \\
\text { depth }\end{array}$ & $\begin{array}{l}\text { Flesh } \\
\text { colour }\end{array}$ \\
\hline \multirow[t]{10}{*}{ II } & $\mathrm{GP} 23, \mathrm{P} 1$ & & 0.011 & 0.042 & & & & \\
\hline & GP86, P1 & & 0.006 & 0.028 & & & & \\
\hline & GP321a, P1 & & 0.033 & & & & & 0.017 \\
\hline & StDND1, P1 & & & & 0.018 & & & 0.031 \\
\hline & StPAD4, P2 & 0.007 & & 0.014 & 0.000 & & & \\
\hline & GP205, P2 & 0.001 & 0.021 & 0.001 & 0.005 & & & \\
\hline & GP86, P2 & 0.000 & 0.010 & 0.001 & 0.014 & & & \\
\hline & GP321a, P2 & 0.000 & 0.022 & 0.001 & 0.023 & & & \\
\hline & GP26, P2 & 0.000 & 0.031 & 0.001 & & & & \\
\hline & StDND1, P2 & 0.007 & & 0.032 & & & 0.031 & \\
\hline \multirow[t]{6}{*}{ III } & GP295, P1 & & & & & & 0.009 & \\
\hline & $\mathrm{BA} 202 \mathrm{k} 7 \mathrm{t} 3 \mathrm{~b}, \mathrm{P} 2$ & & & & & 0.000 & & \\
\hline & GP1a, P2 & & & & & 0.000 & & \\
\hline & GP25, P2 & & & & & 0.000 & 0.007 & \\
\hline & $\mathrm{P} 1 \mathrm{G} 7, \mathrm{P} 2$ & & & & & 0.009 & & \\
\hline & GP295, P2 & 0.019 & & 0.017 & & 0.003 & 0.001 & 0.016 \\
\hline IV & $\mathrm{Ci} 7, \mathrm{P} 1$ & & & & & & & 0.005 \\
\hline \multirow[t]{5}{*}{$\mathrm{V}$} & GP186, P1 & & & & & 0.000 & 0.015 & \\
\hline & BA47f2, P1 & & & & & 0.000 & 0.005 & \\
\hline & CP113, P1 & 0.003 & 0.010 & 0.002 & & & & \\
\hline & GP78, P2 & 0.023 & 0.004 & 0.005 & & & 0.043 & \\
\hline & StNPR1, P2 & & & & & & 0.010 & \\
\hline \multirow[t]{2}{*}{ IX } & GP173b, P2 & & 0.006 & 0.025 & & & & \\
\hline & GP39, P2 & & 0.003 & 0.019 & & & & \\
\hline \multirow[t]{7}{*}{$\mathrm{X}$} & TPT, P1 & & & & & & 0.000 & \\
\hline & TG63, P1 & & & & & & 0.000 & \\
\hline & GP287, P1 & & & & 0.041 & & 0.000 & \\
\hline & CP72, P1 & & & & & & 0.040 & \\
\hline & BA66k2t3, P1 & & & & & & 0.046 & \\
\hline & CP72, P2 & & & & 0.034 & & & \\
\hline & BA113a17, P2 & & & & 0.013 & & & \\
\hline \multirow[t]{3}{*}{ XI } & BA228d $23 \mathrm{t} 3, \mathrm{P} 2$ & & & & 0.021 & 0.008 & & 0.024 \\
\hline & BA88b3t7, P2 & & & & 0.005 & 0.030 & & \\
\hline & GP38, P2 & & & & 0.045 & & & \\
\hline XII & GP229, P1 & & & & & & & 0.006 \\
\hline
\end{tabular}

P-values $\leq 0.01$ are in bold.
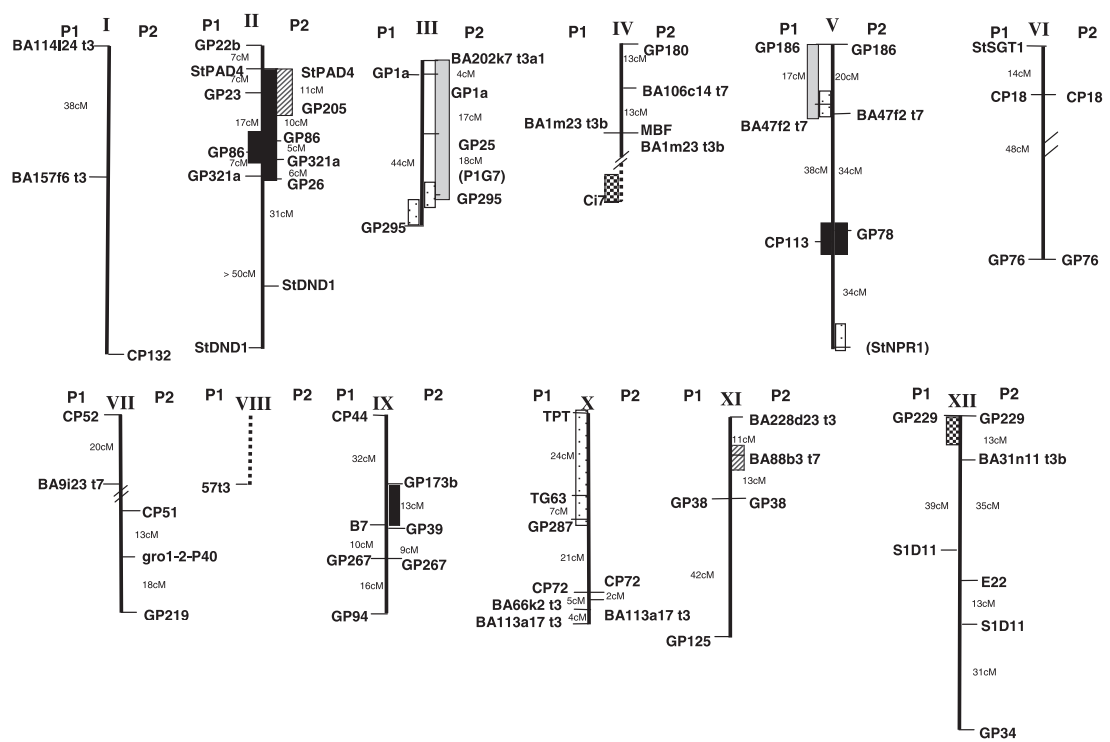

Fig. 2: Population 98-21 - QTL map. Rectangles show locations of quantitative trait loci for sprouting (black), eye depth (dotted), tuber flesh colour (with black and white squares), tuber shape (striped) and shape regularity (grey) 
Table 2: Percent of variance explained by markers $\left(R^{2}\right)$

\begin{tabular}{|c|c|c|c|c|c|c|c|c|}
\hline $\mathrm{Ch}$ & $\begin{array}{l}\text { Marker and } \\
\text { its parental origin }\end{array}$ & $\begin{array}{l}\text { Sprouting } \\
2003\end{array}$ & $\begin{array}{l}\text { Sprouting } \\
2004\end{array}$ & $\begin{array}{l}\text { Sprouting } \\
\text { mean }\end{array}$ & $\begin{array}{l}\text { Tuber } \\
\text { shape }\end{array}$ & $\begin{array}{l}\text { Regularity } \\
\text { of shape }\end{array}$ & $\begin{array}{l}\text { Eye } \\
\text { depth }\end{array}$ & $\begin{array}{l}\text { Flesh } \\
\text { colour }\end{array}$ \\
\hline \multirow[t]{10}{*}{ II } & GP23, P1 & & 3.7 & 3.9 & & & & \\
\hline & GP86, P1 & & 4.9 & 4.2 & & & & \\
\hline & GP321a, P1 & & 3.0 & 3.5 & & & & 3.4 \\
\hline & StDND1, P1 & & & & 3.9 & & & 3.0 \\
\hline & StPAD4, P2 & 4.6 & 2.6 & 4.2 & 8.0 & & & \\
\hline & GP205, P2 & 7.5 & 4.2 & 6.9 & 5.8 & & & \\
\hline & GP86, P2 & 7.7 & 4.1 & 7.0 & 4.0 & & & \\
\hline & GP321a, P2 & 9.2 & 3.2 & 7.1 & 3.5 & & & \\
\hline & GP26, P2 & 9.1 & 2.9 & 6.9 & & & & \\
\hline & StDND1, P2 & 4.3 & & 2.6 & & & 3.7 & \\
\hline \multirow[t]{6}{*}{ III } & GP295, P1 & & & & & & 4.5 & \\
\hline & BA202k7t3b, P2 & & & & & 10.4 & & \\
\hline & GP1a, P2 & & & & & 9.9 & & \\
\hline & GP25, P2 & & & & & 7.6 & 1.9 & \\
\hline & $\mathrm{P} 1 \mathrm{G} 7, \mathrm{P} 2$ & & & & & 5.3 & & \\
\hline & GP295, P2 & 4.2 & & 4.1 & & 6.0 & 6.7 & 3.7 \\
\hline IV & $\mathrm{Ci} 7, \mathrm{P} 1$ & & & & & & & 5.8 \\
\hline \multirow[t]{5}{*}{$\mathrm{V}$} & GP186, P1 & & & & & 9.5 & 4.0 & \\
\hline & BA47f2, P1 & & & & & 10.1 & 7.6 & \\
\hline & CP113, P1 & 4.3 & 3.7 & 4.7 & & & & \\
\hline & GP78, P2 & 3.3 & 6.3 & 5.4 & & & 3.5 & \\
\hline & StNPR1, P2 & & & & & & 5.9 & \\
\hline \multirow[t]{2}{*}{ IX } & GP173b, P2 & & 5.4 & 3.2 & & & & \\
\hline & GP39, P2 & & 5.0 & 3.8 & & & & \\
\hline \multirow[t]{7}{*}{$X$} & TPT, P1 & & & & & & 14.7 & \\
\hline & TG63, P1 & & & & & & 12.1 & \\
\hline & GP287, P1 & & & & 2.7 & & 10.3 & \\
\hline & CP72, P1 & & & & & & 3.3 & \\
\hline & BA66k2t3, P1 & & & & & & 3.1 & \\
\hline & $\mathrm{CP} 72, \mathrm{P} 2$ & & & & 3.0 & & & \\
\hline & BA113a17, P2 & & & & 4.7 & & & \\
\hline \multirow[t]{3}{*}{ XI } & $\mathrm{BA} 228 \mathrm{~d} 23 \mathrm{t} 3, \mathrm{P} 2$ & & & & 3.8 & 3.8 & & 2.7 \\
\hline & BA $88 b 3 t 7$, P2 & & & & 5.6 & 2.6 & & \\
\hline & GP38, P2 & & & & 3.0 & & & \\
\hline XII & GP229, P1 & & & & & & & 5.1 \\
\hline
\end{tabular}

Marker trait linkages significant at $\mathrm{P} \leq 0.01$ are in bold. alleles deteriorating the shape were inherited from P2 and explained up to $10.4 \%$ of the variance (Tables 1 and 2). The second QTL on chromosome V contained alleles from P1 significantly improving the regularity of tuber shape and explaining $10.1 \%$ of the variance. Within the QTL on chromosome XI, the alleles from $\mathrm{P} 2$ also contributed to the more regular tuber shape and explained up to $3.8 \%$ of the variance.

\section{Eye depth QTLs}

This trait was controlled in population $98-21$ by at least four QTLs located on chromosomes III, V and X. The QTL on chromosome $\mathrm{X}$ was the strongest one with marker alleles originating from P1 explaining up to $14.7 \%$ of the variance and contributing to shallower eyes. Two QTLs were detected on chromosome $\mathrm{V}$, the one inherited from $\mathrm{P} 1$ explained $7.6 \%$ of the variance, whereas the QTL inherited from P2 explained $5.9 \%$ of the variance. Marker alleles linked to a QTL on chromosome III inherited from both parents had significant effects on eye depth and explained 4.5 and $6.7 \%$ of the variance.

\section{Tuber flesh colour QTLs}

Two QTLs for whiter tuber flesh colour were located on chromosomes IV and XII and explained 5.8 and $5.1 \%$ of the variance respectively (Tables 1 and 2).
Quantitative trait loci for tuber shape regularity and eye depth on chromosomes III and V at least partially overlapped (Fig. 2).

Interactions between chosen markers were detected at low levels of significance $(0.01<\mathrm{P}<0.05)$ and are not considered further.

\section{Discussion}

Comparison of QTLs tagged for the chosen traits with previous studies indicated diversity within potato gene pool. Tuber dormancy, evaluated here on the basis of sprouting, is a phenomenon still not well characterized. It is quantitatively inherited (Freyre et al. 1994, Van den Berg et al. 1996a). In the first QTL study of tuber dormancy, which was performed on hybrid mapping population consisting of $S$. tuberosum, S. chacoense and Solanum phureja, six QTLs were identified on chromosomes II, III, IV, V, VII and VIII of potato. S. phureja was here a donor of alleles promoting short dormancy (Freyre et al. 1994). In another study, nine QTLs originating from $S$. tuberosum and Solanum berthaultii were mapped on chromosomes I, II, III, IV, V, VIII, IX, X and XI, with the largest effect on chromosome II. In this case, alleles from the wild parent promoted long dormancy (Van den Berg et al. 1996a). Most likely, abscisic acid and ethylene are required for dormancy induction, and abscisic acid maintains bud dormancy, while cytokinins are involved in loss of 
dormancy (Suttle 2004). The most important QTL identified on chromosome II, explaining $31 \%$ of the variance (Van den Berg et al. 1996a) is corresponding to the strongest QTL detected in population 98-21, having in the pedigree six Solanum species. Moreover, QTL controlling abscisic acid content was also localized in the same region of chromosome II as a QTL for dormancy (Šimko et al. 1997). Another study detected in this region not only QTL for abscisic acid content but also for the content of one more plant hormone, a jasmonic acid derivative, called tuberonic acid (Ewing et al. 2004). The role of tuberonic acid and other jasmonates in tuber dormancy is not determined (Suttle 2004). QTLs for dormancy, most probably corresponding to those detected in population $98-21$ on chromosomes $\mathrm{V}$ and IX, were also identified by Freyre et al. (1994) (on chromosomes V and IX) and Van den Berg et al. (1996a,b) (on chromosome V).

In the previous reports, although the putative presence of minor QTLs has been acknowledged, eye depth and tuber shape have been reported as encoded by the two major loci, located close to each other on chromosome X (Van Eck et al. 1994, Li et al. 2005). In the population 98-21, eye depth and tuber shape were influenced by more than two loci and only strong effect of the region on chromosome $\mathrm{X}$ on eye depth was detected, while it had very weak influence on tuber shape. Additional QTLs for eye depth were found on chromosomes III and V. QTLs for tuber shape were in our study detected on chromosomes II and XI. This situation can be explained by a very limited resolution of our genetic map, which leaves a possibility of omission of the certain locus on chromosome X. When we compared the maps of chromosome $\mathrm{X}$ on the basis of common markers and intervals between them (http: //gabi.rzpd.de/database/maps.shtml) both loci Ro/ro and Eyd/eyd (Van Eck et al. 1994, Li et al. 2005) theoretically were located between markers TPT and TG63 scored in population 98-21. Although the gap between these markers is big $(24 \mathrm{cM})$, we still suspect that the effect of $R o /$ ro locus should be detectable by these markers, as the locus Eyd/eyd was. Other explanation is that locus Ro/ro was described in a hybrid population possessing S. tuberosum, S. phureja and $S$. vernei in pedigree (Van Eck et al. 1994), while in population 98-21 different species could have contributed different loci. In one more population, QTLs for tuber shape have been mapped to chromosomes VII, XII and unassigned linkage group that could be chromosome X (Sørensen 2006). The linkage of deep eyes with round shape of tubers described previously (Li et al. 2005), was in population 98-21 observed only as a very weakly significant correlation.

The least is known about the inheritance of tuber shape regularity, as it is a complex trait depending on many components, such as depths of indentations, presents of various tuber defects and uniformity of tuber shape (Domański 2001). Nevertheless, it is an important trait in potato breeding (Kerlan and Ellisèche 2000, Domański 2001). In population 98-21 two QTLs for the shape regularity were identified on chromosomes III and V, partially overlapping with minor QTLs for eye depth.

Tuber flesh colour depends on carotenoid content. Locus $Y / y$ on chromosome III conferring different tuber flesh colours (Bonierbale et al. 1988, Brown et al. 1993) has been shown to overlap on Solanaceae synteny map with a QTL for a carotenoid-dependant red pigmentation of Capsicum annum fruit (Thorup et al. 2000, Ben Chaim et al. 2001). Moreover, two candidate genes encoding $\beta$-carotene hydroxylase and phytoene synthase, located in the corresponding position and involved in carotenoid metabolism, have been identified in tomato (Thorup et al. 2000). In population 98-21 two QTLs for tuber flesh colour were identified on chromosomes IV and XII, even though a minor putative QTL was also detected on chromosome III. We can hypothesize that the genotypes of both parents were $y / y$ and the pale yellow colour of $\mathrm{P} 2$ was due to minor modifying genes, as yellow flesh was observed in only one individual and deep yellow flesh was not observed at all in the progeny. However, we cannot exclude that locus $Y / y$ plays an important role in flesh colour determination also in population 98-21, especially because the QTLs on chromosome IV and XII explained only small fractions of variance observed for this trait and because the number of mapped markers was limited.

It cannot be excluded that different wild species contributed to the various mapping populations and most likely brought in new alleles, but maybe also new loci. Most likely the number of the detected QTLs was not exhausted and the accuracy of their chromosomal localization was low because of poor resolution of our genetic map. Nevertheless, novel QTLs for most of the investigated traits were detected in the population 98-21. There were also QTLs that seemed to be universal e.g. QTL for dormancy on chromosome II (Freyre et al. 1994, Van den Berg et al. 1996a) or QTL for eye depth on chromosome X (Li et al. 2005).

On the basis of assessment of numerous traits, with the traits described here among them, promising clones combining late blight resistance with decent level of tuber characteristics were selected from population 98-21 for prebreeding of parental lines for new potato cultivars.

\section{Acknowledgements}

The authors thank Professor E. Zimnoch-Guzowska and Dr W. Marczewski for the critical reading of the manuscript.

\section{References}

Ben Chaim, A., I. Paran, R. C. Grube, M. Jahn, R. van Wijk, and J. Peleman, 2001: QTL mapping of fruit-related traits in pepper (Capsicum annuum). Theor. Appl. Genet. 102, 1016-1028.

Bonierbale, M. W., R. L. Plaisted, and S. D. Tanksley, 1988: RFLP maps based on common set of clones reveal modes of chromosomal evolution in potato and tomato. Genetics 120, 1095-1103.

Brown, C. R., C. G. Edwards, C-P. Yang, and B. B. Dean, 1993 Orange flesh trait in potato: inheritance and carotenoid content. J. Am. Soc. Hortic. Sci. 118, 145-150.

Domański, L., 2001: Assessment of Morphological Characters of Potato Tubers. Monografie i Rozprawy Naukowe IHAR, Radzików, Poland 10a, 92-95.

Ewing, E. E., I. Simko, E. A. Omer, and P. J. Davies, 2004: Polygene mapping as a tool to study the physiology of potato tuberization and dormancy. Am. J. Potato Res. 81, 281-289.

FAOSTAT, 2006. Food and Agricultural Organization of the United Nations Statistical Database, http://faostat.fao.org.

Freyre, R., S. Warnke, B. Sosinski, and D. S. Douches, 1994: Quantitative trait locus analysis of tuber dormancy in diploid potato (Solanum spp.). Theor. Appl. Genet. 89, $474-480$.

Kerlan, M. C., and D. Ellisèche, 2000: Tuber quality: objectives in breeding and breeding research. Plant Breeding and Seed Sci. 44, $21-35$.

Li, X.-Q., H. De Jong, D. M. De Jong, and W. S. De Jong, 2005 Inheritance and genetic mapping of tuber eye depth in cultivated diploid potatoes. Theor. Appl. Genet. 110, 1068-1073. 
Mullins, E., D. Milbourne, C. Petti, B. M. Doyle-Prestwich, and C. Meade, 2006: Potato in the age of biotechnology. Trends Plant Sci. 11, 254-260.

Ortiz, R., and Z. Huaman, 1994: Inheritance of morphological and tuber characteristics. In: J. E. Bradshaw, G. R., Mackay (eds), Potato Genetics, 263-283. CAB International, Wallinford.

Reust, W., 1986: EAPR working group 'Physiological age of the potato'. Potato Res. 29, 268-279.

Ritter, E., C. Gebhardt, and F. Salamini, 1990: Estimation of recombination frequencies and construction of RFLP linkage maps in plants from crosses between heterozygous parents. Genetics 125, $645-654$.

Sørensen, K. K., 2006: Mapping of morphological traits and associations with late blight resistance in Solanum tuberosum and $S$. vernei In: QTLs for Foliage Late Blight Resistance from Solanum vernei, 93-122. PhD thesis. Danish Institute of Agricultural Sciences, Royal Veterinary and Agricultural University, Frederiksberg, Denmark.

Šimko, I., S. McMurry, H.-M. Yang, A. Manschot, P. J. Davies, and E. E. Ewing, 1997: Evidence from polygene mapping for a causal relationship between potato tuber dormancy and abscisic acid content. Plant Physiol. 115, 1453-1459.

Śliwka, J., H. Jakuczun, R. Lebecka, W. Marczewski, C. Gebhardt, and E. Zimnoch-Guzowska, 2007: Tagging QTLs for late blight resistance and plant maturity from diploid wild relatives Solanum verrucosum and $S$. microdontum in a cultivated potato ( $S$. tuberosum) background. Theor. Appl. Genet. Published online 28th April 2007, doi: 10.1007/s00122-007-0546-9.

Suttle, J. C., 2004: Physiological regulation of potato tuber dormancy. Am. J. Potato Res. 81, 253-262.

Tarn, T. R., G. C. C. Tai, H. de Jong, A. M. Murphy, and J. E. A. Seabrook, 1993: Breeding potatoes for long-day, temperate climates. In: J. Janick (ed.), Plant Breeding Reviews 9, 217-332.

Thorup, T. A., B. Tanyolac, K. D. Livingstone, S. Popovsky, I. Paran, and M. Jahn, 2000: Candidate gene analysis of organ pigmentation loci in the Solanaceae. Proc. Natl Acad. Sci. USA 97, $11192-11197$.

Van den Berg, J. H., E. E. Ewing, R. L. Plaisted, S. McMurray, and M. W. Bonierbale, 1996a: QTL analysis of potato tuber dormancy. Theor. Appl. Genet. 93, 317-324.

Van den Berg, J. H., E. E. Ewing, R. L. Plaisted, S. McMurray, and M. W. Bonierbale, 1996b: QTL analysis of potato tuberization. Theor. Appl. Genet. 93, 307-316.

Van Eck, H. J., J. M. E. Jacobs, P. Stam, J. Ton, W. J. Stiekema, and E. Jacobsen, 1994: Multiple alleles for tuber shape in diploid potato detected by qualitative and quantitative genetic analysis using RFLPs. Genetics 137, 303-309.

Zimnoch-Guzowska, E., 2002: Hodowla ziemniaka - zespolenie nowoczesnych metod i technik. Zeszyty Problemowe Postępów Nauk Rolniczych 488, 63-70. 